\title{
Facile Synthesis of a Hydroxyl-Functionalized Tröger's
}

\section{Base Diamine: A New Building Block for High-Performance Polyimide Gas Separation Membranes}

\author{
Xiaohua Ma ${ }^{\mathrm{a}}$, Mahmoud Abdulhamid ${ }^{\mathrm{a}}$, Xiaohe Miao $^{\mathrm{b}}$, Ingo Pinnau* ${ }^{\mathrm{a} *}$
}

King Abdullah University of Science and Technology (KAUST),

${ }^{\mathrm{a}}$ Functional Polymer Membranes Group, Advanced Membranes and Porous Materials Center, Division of Physical Sciences, ${ }^{\mathrm{b}}$ Imaging and Characterization Core Lab, Thuwal 23955-6900, KSA.

E-mail: Ingo.Pinnau@kaust.edu.sa

Keywords: Intrinsically microporous polyimides, hydroxyl-functionalized Tröger's base, hydrogen bonding, gas separation membranes 


\begin{abstract}
Two intrinsically microporous polyimides (PIM-PIs) were synthesized by polycondensation reaction of 4,4'-(hexafluoroisopropylidene)diphthalic anhydride (6FDA) and 3,3,3',3'tetramethyl-spirobisindane-6,7,6',7'-tetracarboxylic dianhydride (SBI) with a newly designed ortho-hydroxyl-functionalized Tröger's base diamine, 1,7-diamino-6H,12H-5,11methanodibenzo[1,5]diazocine-2,8-diol (HTB). Both amorphous PIM-PIs were soluble in aprotic solvents and showed excellent thermal stability with onset decomposition temperature of $\sim 380^{\circ} \mathrm{C}$. SBI-HTB displayed higher $\mathrm{CO}_{2}$ permeability (466 vs. 67 Barrer) than 6FDA-HTB but significantly lower selectivity for $\mathrm{CO}_{2} / \mathrm{CH}_{4}(29$ ss 73$), \mathrm{H}_{2} / \mathrm{CH}_{4}(29 v s 181), \mathrm{O}_{2} / \mathrm{N}_{2}(4.6 v s$ 6.0) and $\mathrm{N}_{2} / \mathrm{CH}_{4}(1$ vs 2.5$)$. 6FDA-HTB displayed the highest gas-pair permselectivity values of all reported OH-functionalized PIM-PIs to date. The high permselectivity of 6FDA-HTB resulted primarily from exceptional diffusion selectivity due to strong size-sieving properties caused by hydrogen bonding between the proton of the hydroxyl group and the nitrogen atoms in the tertiary amine of the Tröger's base $(\mathrm{O}-\mathrm{H} \cdots \mathrm{N})$.
\end{abstract}




\section{INTRODUCTION}

Aromatic polyimides are among the most promising membrane materials for large-scale industrial gas separation applications. ${ }^{1-4}$ Early studies demonstrated good performance for $\mathrm{CO}_{2} / \mathrm{CH}_{4}$ separation of solution-processable polyimides derived from 4,4'(hexafluoroisopropylidene)diphthalic anhydride (6FDA) and pyromellitic dianhydride (PMDA) with various aromatic diamines. ${ }^{5-6}$ Specifically, 6FDA-based polyimides made from commercially available hydroxyl-functionalized diamines demonstrated extraordinarily high $\mathrm{CO}_{2} / \mathrm{CH}_{4}$ selectivity of up to $\sim 100$ with moderate $\mathrm{CO}_{2}$ permeability of $\sim 5-10$ Barrer (1 Barrer $\left.=1 \times 10^{-10} \mathrm{~cm}^{3}(\mathrm{STP}) \mathrm{cm} \mathrm{cm}^{-2} \mathrm{~s}^{-1} \mathrm{cmHg}^{-1}\right)^{7-9}$

One strategy to enhance the gas permeability in glassy polymers is to incorporate sterically hindered building blocks in the polymer backbone to disrupt efficient chain packing. ${ }^{10-12}$ This concept has been successfully applied to the synthesis of microporous ladder polymers (PIMs) and polyimides of intrinsic microporosity (PIM-PIs). ${ }^{13-15}$ The first PIM-PIs, made by reaction of custom-designed spirobisindane-derived dianhydrides (SBI) and a series of commercially available diamines, were characterized by high Brunauer-TellerEmmett (BET) surface areas of up to $\sim 700 \mathrm{~m}^{2} \mathrm{~g}^{-1}$ and exhibited high gas permeabilities with moderate gas-pair selectivities with overall performance close to the 2008 permeability/selectivity upper bound. ${ }^{16-19}$ PIM-PIs made from ethanoanthracene-, triptycene-, spirobifluorene-, and carbocyclic pseudo Tröger's base-derived dianhydrides with conventional diamines also exhibited high permeability and moderate selectivity. ${ }^{20-24}$ To boost selectivity, a series of high-performance PIM-PIs was designed for membrane-based natural gas separation derived from bulky triptycene-based dianhydrides and commercially available hydroxyl-functionalized diamines..$^{25-28}$ For example, PIM-PI synthesized from 9,10diisopropyl-triptycene-based dianhydride (TPDA) and 4,6-diaminoresorcinol (DAR) displayed excellent performance with $\mathrm{CO}_{2}$ permeability of 215 Barrer and $\mathrm{CO}_{2} / \mathrm{CH}_{4}$ selectivity of $46 .^{25}$ Interestingly, relatively few $\mathrm{OH}$-functionalized diamines bearing sterically 
restricted contortion sites have been reported. PIM-PIs made from 6FDA and dihydroxylbased spirobisindane-, spirobifluorene- and triptycene-diamines have shown promising performance for $\mathrm{CO}_{2} / \mathrm{CH}_{4}$ and $\mathrm{H}_{2} \mathrm{~S} / \mathrm{CH}_{4}$ separation. ${ }^{29-33}$

Mckeown and co-workers pioneered the use of Tröger's base (TB) derivatives as versatile new building blocks for the synthesis of PIM ladder polymers and PIM-PIs. ${ }^{34-36}$ Tröger's base is a chiral molecule containing a rigid, V-shaped tertiary amine diazocine bridge. ${ }^{37}$ Several polyimides made by polycondensation reaction of various dianhydrides with methyl- and bromo-substituted TB diamines demonstrated promising performance for gas separation applications, particularly for $\mathrm{CO}_{2} / \mathrm{CH}_{4}$ separation. ${ }^{38-43}$ Here, we report PIM-PIs with excellent gas separation properties made from a novel hydroxyl-functionalized Tröger's base diamine (HTB). The synthetic procedures are shown in Scheme 1.

Scheme 1. Synthetic Routes of the Ortho-Hydroxyl-Functionalized Tröger's Base-Based PIM-PIs (6FDA-HTB and SBI-HTB).
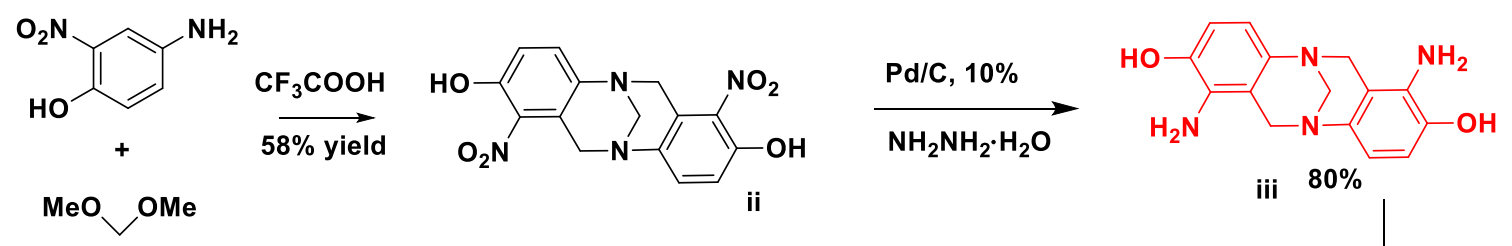

iii $80 \%$

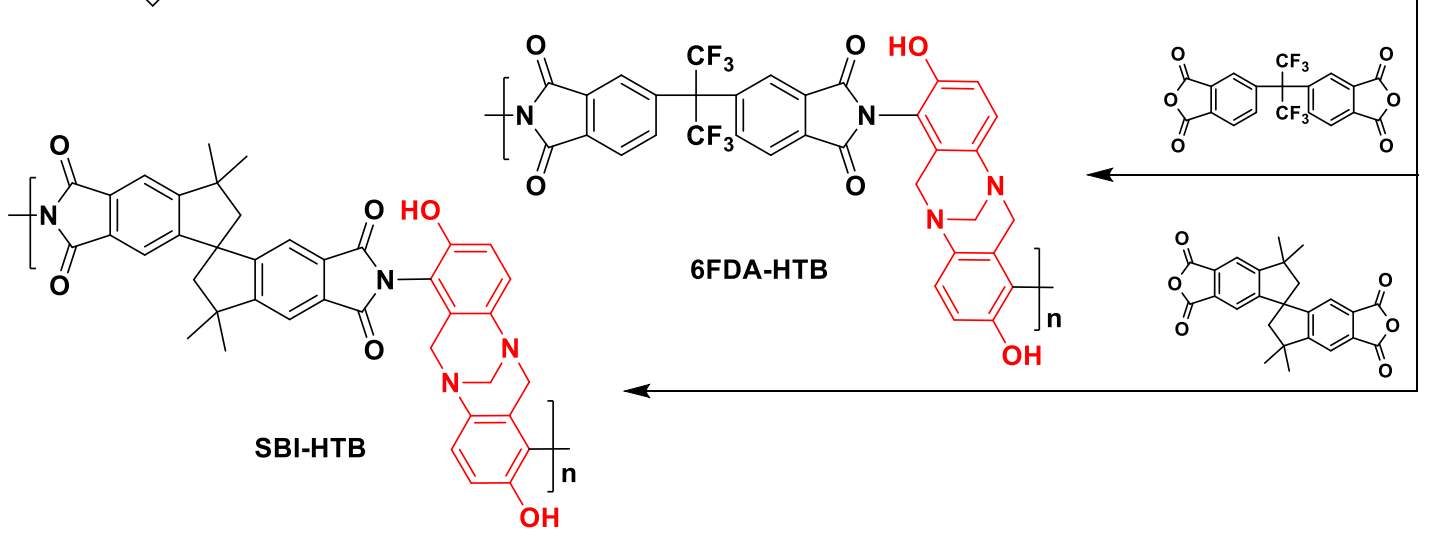




\section{EXPERIMENTAL SECTION}

Materials. 4,4'-(Hexafluoroisopropylidene)diphthalic anhydride (6FDA, 99\%), trifluoroacetic acid, 4-amino-2-nitrophenol and dimethoxymethane, silica gel, dichloromethane, anhydrous $m$-cresol, tetrahydrofuran, isoquinoline, and anhydrous $N, N^{\prime}-$ dimethylformamide were obtained from Sigma-Aldrich and used as received. 3,3,3',3'Tetramethyl-1,1'-spirobisindane-5,5',6,6'-tetracarboxylic anhydride (SBI) was synthesized according to a previously reported procedure. ${ }^{17}$

Characterization and Methods. ${ }^{1} \mathrm{H}$ NMR and ${ }^{13} \mathrm{C}$ NMR spectra of the monomer and polymers were recorded with a Bruker AVANCE-III spectrometer at a frequency of 400 or $500 \mathrm{MHz}$ in deuterated chloroform or deuterated dimethylsulfone with tetramethylsilane as an internal standard; the chemical shifts were recorded in ppm. Proton 2D NOESY spectrum for 6FDA-HTB was performed using a Bruker AVANCE-III 950 MHz NMR instrument; DMSO$d_{6}$ was used as solvent. Molecular weight $\left(\mathrm{M}_{\mathrm{n}}\right)$ and molecular weight distribution (PDI) of the polymers were obtained by gel permeation chromatography (GPC, Malvern HT-350 and Agilent GPC 1200) using dimethylformamide (DMF) as solvent and polystyrene as external standard. High-resolution mass spectroscopy (HRMS) of the monomer was conducted on a Thermo LC/MS system with LTQ Orbitrap Velos detectors. Thermal gravimetric analysis (TGA) was carried out with a TGA Q5000 equipped with a thermal analyzer and quadrupole mass spectrometer (Aëolos QMS 403 C) employing helium as the carrier gas. Differential scanning calorimetric analysis (DSC) and melting point of the polymers and intermediates were recorded on a DSC Q2000. Density was obtained using a Mettler-Toledo balance equipped with a density measurement kit based on Archimedes' principle using iso-octane as the reference liquid. The BET surface area of the polymers was measured by $\mathrm{N}_{2}$ adsorption at $-196{ }^{\circ} \mathrm{C}$ (Micrometrics ASAP 2020); each sample was degassed at $150{ }^{\circ} \mathrm{C}$ for $12 \mathrm{~h}$ before testing. $\mathrm{CO}_{2}$ adsorption was also performed on a Micrometrics ASAP 2020 at $0{ }^{\circ} \mathrm{C}$ and up to 1 bar. The pore size distributions of the polymers were derived from $\mathrm{CO}_{2}$ adsorption using the 
NLDFT model. $\mathrm{CO}_{2}$ and $\mathrm{CH}_{4}$ solubility was determined gravimetrically at 2 bar and $35{ }^{\circ} \mathrm{C}$ using an IGA-003 instrument (Hiden Isochema). Single-crystal diffraction of the intermediate 1,7-dinitro-6H,12H-5,11-methanodibenzo[1,5]diazocine-2,8-diol compound was carried out on a Bruker single-crystal diffractometer using $\mathrm{Cu}(\mathrm{K} \alpha)$ as the X-ray source. Dynamic mechanical stress-strain curves of the polymers were measured using a dynamic mechanical analyzer (DMA, TA Instruments Q800). The samples were kept at $35{ }^{\circ} \mathrm{C}$ for one minute and then ramped at $3 \mathrm{~N} / \mathrm{min}$ to $18 \mathrm{~N}$.

Synthesis of 1,7-dinitro-6H,12H-5,11-methanodibenzo[1,5]diazocine-2,8-diol. 4Amino-2-nitrophenol $(7.70 \mathrm{~g}, 50.0 \mathrm{mmol})$ and dimethoxymethane $(9.50 \mathrm{~g}, 2.5$ equiv, 125 mmol) were added to a $250 \mathrm{~mL}$ three-neck flask and cooled to $-20{ }^{\circ} \mathrm{C}$. To it, $\mathrm{CF}_{3} \mathrm{COOH}(100$ $\mathrm{mL}$ ) was added dropwise over $1 \mathrm{~h}$. The resulting solution was stirred at room temperature for $48 \mathrm{~h}$ and then poured into ice water $(300 \mathrm{~mL})$. The system was extracted five times $(5 \times 100$ $\mathrm{mL}$ ) with dichloromethane. The organic phase was combined and dried with magnesium sulfate, further concentrated by rota-evaporation and then loaded in a column packed with silica gel $(200 \sim 300 \mathrm{mesh})$. A reddish solid (5.00 g, 58.1\% yield) was obtained after column chromatography. mp: $266.2{ }^{\circ} \mathrm{C}$. TLC: dichloromethane/ethyl acetate $=8 / 1, \mathrm{R}_{\mathrm{f}}=0.25 .{ }^{1} \mathrm{H}$ NMR (400 MHz, $\left.\mathrm{CDCl}_{3}\right): \delta 10.68(\mathrm{~s}, 2 \mathrm{H}), 7.43(\mathrm{~d}, 2 \mathrm{H}, J=9.1 \mathrm{~Hz}), 7.08(\mathrm{~d}, 2 \mathrm{H}, J=9.1 \mathrm{~Hz})$, $4.98(\mathrm{~d}, 2 \mathrm{H}, J=18.2 \mathrm{~Hz}), 4.48(\mathrm{~d}, 2 \mathrm{H}, J=18.2 \mathrm{~Hz}), 4.26(\mathrm{~s}, 2 \mathrm{H})$.

Synthesis of 1,7-diamino-6H,12H-5,11-methanodibenzo[1,5]diazocine-2,8-diol. 1,7Dinitro-6H,12H-5,11-methanodibenzo[1,5]diazocine-2,8-diol (2.00 g, $5.81 \mathrm{mmol})$ was added to $N, N$-dimethylformamide $(80 \mathrm{~mL})$ in a $250 \mathrm{~mL}$ three-neck flask. To it, hydrazine monohydrate $(2.0 \mathrm{~mL}, 70 \mathrm{wt} \%)$ and palladium on carbon $(10 \%, 100 \mathrm{mg})$ were added in sequence under $\mathrm{N}_{2}$ flow. The system was heated at $130{ }^{\circ} \mathrm{C}$ for $2 \mathrm{~h}$ and then cooled to room temperature. The solution was filtered through a Celite pad into $200 \mathrm{~mL}$ ice-cold dichloromethane. White microcrystals were formed, collected by filtration and dried in a 
vacuum oven at $135^{\circ} \mathrm{C}$ for $24 \mathrm{~h}$. An off-white powder (1.32 g, yield: $\left.80 \%\right)$ was obtained and used directly for polymerization reactions. mp: $344.2{ }^{\circ} \mathrm{C} ;{ }^{1} \mathrm{H}$ NMR $\left(500 \mathrm{MHz}, \mathrm{DMSO}-d_{6}\right): \delta$ $8.66(\mathrm{~s}, 2 \mathrm{H}), 6.47(\mathrm{~d}, 2 \mathrm{H}, J=8.35 \mathrm{~Hz}), 6.18(\mathrm{~d}, 2 \mathrm{H}, J=8.35 \mathrm{~Hz}), 4.17(\mathrm{~m}, 6 \mathrm{H}), 3.94(\mathrm{~s}, 2 \mathrm{H})$, $3.82(\mathrm{~d}, 2 \mathrm{H}, J=7.7 \mathrm{~Hz}) .{ }^{13} \mathrm{C}$ NMR $\left(125 \mathrm{MHz}, \mathrm{DMSO}-d_{6}\right): \delta 141.2,139.6,132.6,114.2,113.2$, 112.6, 66.3, 56.3. HRMS (APPI) m/z: $[\mathrm{M}+\mathrm{H}]^{+}$: calcd. for $\mathrm{C}_{15} \mathrm{H}_{17} \mathrm{~N}_{4} \mathrm{O}_{2}$ : 285.1346; Found: 285.1346 .

Synthesis of 6FDA-HTB. 4,4'-(Hexafluoroisopropylidene)diphthalic anhydride (444.4 $\mathrm{mg}, \quad 1.00 \mathrm{mmol})$ and 1,7-diamino-6H,12H-5,11-methanodibenzo[1,5]diazocine-2,8-diol (284.1 mg, $1.00 \mathrm{mmol})$ were added to $m$-cresol $(3.6 \mathrm{~mL})$ and flushed with $\mathrm{N}_{2}$. The system was stirred at room temperature for $15 \mathrm{~min}$ and then at $60{ }^{\circ} \mathrm{C}$ for $1 \mathrm{~h}$ to form a clear solution. A drop of isoquinoline was added and the solution was heated to $180^{\circ} \mathrm{C}$ for $3 \mathrm{~h}$. Thereafter, the viscous solution was precipitated in methanol and the solid was collected by filtration. Traces of remaining $m$-cresol in the polymer were removed by Soxhlet extraction using methanol as solvent. The polyimide 6FDA-HTB was obtained as light yellow filaments (690 mg, yield: $96 \%$ ) after drying in an vacuum oven at $120^{\circ} \mathrm{C}$ for $24 \mathrm{~h} .{ }^{1} \mathrm{H}$ NMR $\left(500 \mathrm{MHz}, \mathrm{DMSO}-d_{6}\right): \delta$ $9.61(\mathrm{~s}, 2 \mathrm{H}), 8.16(\mathrm{~s}, 2 \mathrm{H}), 7.96(\mathrm{~s}, 2 \mathrm{H}), 7.84(\mathrm{~s}, 2 \mathrm{H}), 7.02(\mathrm{~s}, 2 \mathrm{H}), 6.78(\mathrm{~s}, 2 \mathrm{H}), 4.24(\mathrm{~s}, 2 \mathrm{H})$, $4.03(\mathrm{~s}, 4 \mathrm{H})$. FT-IR (polymer film, $\left.v, \mathrm{~cm}^{-1}\right): 2200 \sim 3700$ (s, br, -OH), 2931 (s, m, C-H), 1788, 1719 (s, str, imide), $1380-1600(\mathrm{~m}, \mathrm{str}, \mathrm{ph}), 1251$ (m, str, C-F). The onset of polymer degradation $\left(\mathrm{T}_{\mathrm{d} \text {, onset }}\right)$ commenced at $\sim 380^{\circ} \mathrm{C} ; \mathrm{S}_{\mathrm{BET}}=340 \mathrm{~m}^{2} / \mathrm{g}$.

Synthesis of SBI-HTB. The general synthetic procedure of SBI-HTB was the same as for 6FDA-HTB. The polymer was obtained as light yellow powder with a yield of $96 \% .{ }^{1} \mathrm{H}$ NMR (400 MHz, DMSO-d $\left.d_{6}\right): \delta 9.53(\mathrm{~s}, 2 \mathrm{H}), 7.95(\mathrm{~s}, 2 \mathrm{H}), 7.31(\mathrm{~s}, 2 \mathrm{H}), 7.00(\mathrm{~s}, 2 \mathrm{H}), 6.72(\mathrm{~s}, 2 \mathrm{H})$, $4.20(\mathrm{~s}, 2 \mathrm{H}), 3.92(\mathrm{~s}, 4 \mathrm{H}), 2.34(\mathrm{~m}, 4 \mathrm{H}), 1.51(\mathrm{~d}, 12 \mathrm{H}, J=5.3 \mathrm{~Hz})$. FT-IR (polymer film, $v$, $\mathrm{cm}^{-1}$ ): $2200 \sim 3700$ (s, br, -OH), 2931 (s, m, C-H), 1788, 1719 (s, str, imide), $1380-1600$ (m, str, ph). $\mathrm{T}_{\mathrm{d} \text {, onset }}$ commenced at $\sim 380{ }^{\circ} \mathrm{C} ; \mathrm{S}_{\mathrm{BET}}=400 \mathrm{~m}^{2} / \mathrm{g}$. 
Film Preparation. The HTB-based PIM-PIs were dissolved in DMF (3-5 wt/v\%) and purified using small $1.0 \mu \mathrm{m}$ PTFE filter cartridges. The solutions were carefully transferred into a flat glass Petri dish covered by a larger Petri dish to control the evaporation rate under $\mathrm{N}_{2}$ flow. The solvent was evaporated for at least 2 days and dry polymer films $(\sim 40$ to $60 \mu \mathrm{m})$ were obtained. Finally, each film was dried in a vacuum oven at $250{ }^{\circ} \mathrm{C}$ for $24 \mathrm{~h}$. Complete solvent removal was confirmed by TGA analysis.

\section{RESULTS AND DISCUSSION}

Synthesis, Structure and Physical Properties of the Polyimides. The synthesis of the orthohydroxyl-functionalized Tröger's base-based diamine was performed by the following steps: First, 4-amino-2-nitrophenol was reacted with dimethoxymethane in trifluoroacetic acid acting both as solvent and catalyst to give 1,7-dinitro-6H,12H-5,11methanodibenzo[1,5]diazocine-2,8-diol as reddish crystals. Single-crystal data (ESI) confirmed the cleft-like structure with a $\mathrm{C} 2$ symmetric axis of the dinitrol compound, as shown in Figure 1. Surprisingly, no isomers were formed - the Tröger's base formation reaction occured only at the $\mathrm{C} 3$-position (ortho to the $\mathrm{NO}_{2}$ group). Hence, the two $\mathrm{NO}_{2}$ groups are positioned orthogonal to the Tröger's base bridge, which gives rise to a sterically hindered and twisted structure.

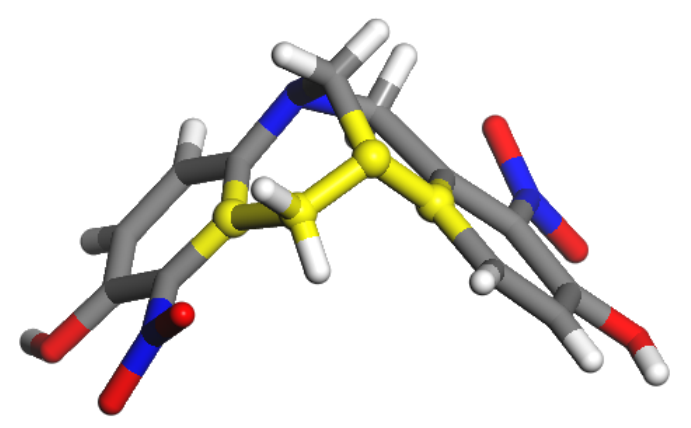

Figure 1. Single-crystal molecular structure of 1,7-dinitro-6H,12H-5,11-methanodibenzo[1,5] diazocine-2,8-diol. The dihedral angle is highlighted as yellow bond. 
The second synthetic step was the reduction of the dinitrol intermediate to the diamine, which was conducted by a standard procedure using hydrazine monohydrate and palladium on activated carbon as catalyst in DMF. After filtration through a Celite pad into a large amount of dichloromethane, the diamine compound was obtained as off-white microcrystals. The monomer was then reacted with 6FDA and SBI in $m$-cresol under catalytic amount of isoquinoline. The resulting hydroxyl-functionalized polyimides, 6FDA-HTB and SBI-HTB, were readily soluble in highly polar aprotic solvents such as DMF, NMP, DMAc and $m$-cresol (Table S1) and had high $\mathrm{M}_{\mathrm{n}}$ of $\sim 330 \mathrm{~kg} \mathrm{~mol}^{-1}$ and narrow polydispersity index (PDI) of $\sim 1.2$ (Table 1).

Table 1. Physical Properties of the OH-Functionalized Tröger's Base Polyimides.

\begin{tabular}{lccccc}
\hline Polymer & $\mathrm{M}_{\mathrm{n}}\left(\mathrm{g} \mathrm{mol}^{-1}\right)^{\mathrm{a}}$ & PDI & $\mathrm{S}_{\mathrm{BET}}\left(\mathrm{m}^{2} \mathrm{~g}^{-1}\right)$ & $\mathrm{T}_{\mathrm{d}, \text { onset }}\left({ }^{\circ} \mathrm{C}\right)$ & $\rho\left(\mathrm{g} \mathrm{cm}^{-3}\right)$ \\
\hline 6FDA-HTB $^{\mathrm{a}}$ & $35.3 \times 10^{4}$ & 1.19 & 340 & 380 & 1.46 \\
SBI-HTB $^{\mathrm{a}}$ & $33.7 \times 10^{4}$ & 1.23 & 400 & 380 & 1.26 \\
\hline
\end{tabular}

${ }^{a}$ The molecular weight of the polymer was determined by GPC using DMF as solvent.

The proton NMR spectra of the monomer and polymers are shown in Figure 2. Similar to previously reported ortho-hydroxyl-functionalized PIM-PIs, ${ }^{29,}{ }^{44}$ 6FDA-HTB and SBI-HTB showed much broader peaks than those displayed in the $\mathrm{OH}$-functionalized diamine monomer (Figure 2a). In addition, a large shift of the hydroxyl group towards lower field from 8.66 ppm of the monomer to $9.60 \mathrm{ppm}$ of the polyimides was observed. This effect resulted from the change in the chemical environmental of the ortho-positioned $\mathrm{OH}$ groups from the amine to the imide group. Strong interaction between the proton of the $\mathrm{OH}$ group and the protons in the Tröger's base due to hydrogen bonding was confirmed by the 2D NOESY NMR spectrum of 6FDA-HTB, indicating that these protons were in the range below $5 \AA$ even when dissolved in polar DMSO (Figure 2b). ${ }^{45}$ 

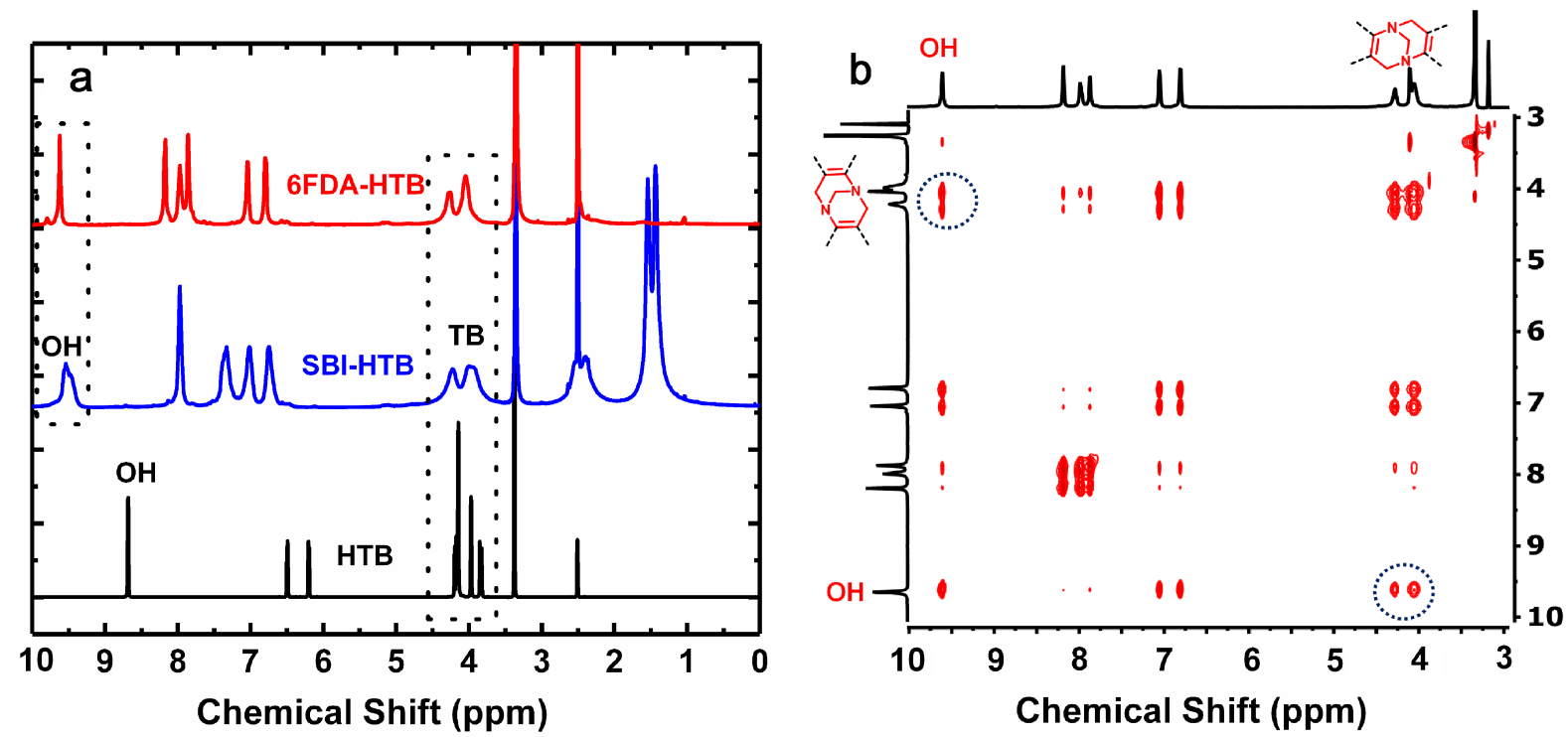

Figure 2. a) ${ }^{1} \mathrm{H}$ NMR of the hydroxyl-functionalized Tröger's base-based diamine monomer (HTB) in comparison with 6FDA-HTB and SBI-HTB polyimides in DMSO- $d_{6}$ solution; b) Proton 2D NOESY of 6FDA-HTB in DMSO- $d_{6}$ solution.

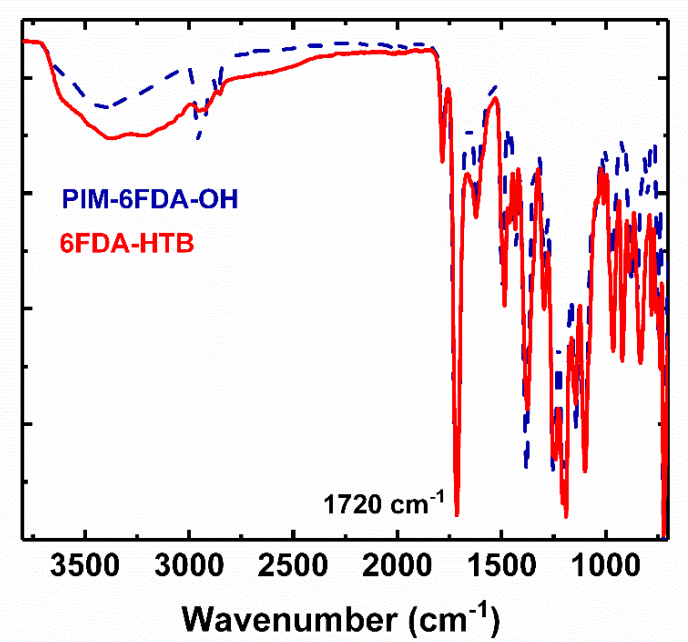

Figure 3. FT-IR spectra of 6FDA-HTB and PIM-6FDA-OH.

The FT-IR spectra of 6FDA-HTB and a previously reported OH-functionalized, spirobisindane-derived PIM-PI (PIM-6FDA-OH) are shown in Figure 3. After normalization of the spectra at $1720 \mathrm{~cm}^{-1}$, a much broader and more intensive $\mathrm{OH}$ bond was observed in 
6FDA-HTB (3700 to $2200 \mathrm{~cm}^{-1}$ ) than in PIM-6FDA-OH (3700 to $\left.2900 \mathrm{~cm}^{-1}\right)$. This result indicates stronger hydrogen bonding in 6FDA-HTB than in PIM-6FDA-OH according to previous findings. ${ }^{46}$ The effects of hydrogen bonding on the gas transport properties of 6FDAHTB are discussed in more detail below.

Thermal and Mechanical Properties of the Polymers. 6FDA-HTB and SBI-HTB demonstrated high thermal stability with onset decomposition temperature of $\sim 380{ }^{\circ} \mathrm{C}$ (Figure S1a and Table 1). No glass transition temperature was detected in the $\mathrm{OH}-$ functionalized Tröger's base polyimides by DSC scans up to $350{ }^{\circ} \mathrm{C}$ (Figure S1b). 6FDAHTB demonstrated excellent mechanical properties with a Young's modulus of $2.44 \mathrm{GPa}$ and elongation at break of 6\% (Table S2; Figure S2).

Intrinsic Microporosity of the Polyimides. The microporosity of the polyimides was evaluated by $\mathrm{N}_{2}$ adsorption at $-196{ }^{\circ} \mathrm{C}$ up to 1 bar. All polyimides demonstrated Type I adsorption isotherms, as shown in Figure 4a, with remarkable microporosity as indicated by large gas sorption uptake at very low relative pressure $\left(\mathrm{p} / \mathrm{p}_{0}<0.05\right) .6$ FDA-HTB showed high BET surface area of $340 \mathrm{~m}^{2} \mathrm{~g}^{-1}$, which is the highest value among all 6FDA-based OHfunctionalized PIM-PIs, including spirobisindane-based PIM-6FDA-OH $\left(190 \mathrm{~m}^{2} \mathrm{~g}^{-1}\right)^{29}$, spirobifluorene-based 6FDA-HSBF $\left(70 \mathrm{~m}^{2} \mathrm{~g}^{-1}\right)^{32}$ and triptycene-based 6FDA-DAT1-OH (160 $\left.\mathrm{m}^{2} \mathrm{~g}^{-1}\right){ }^{33}$ SBI-HTB had a higher surface area of $400 \mathrm{~m}^{2} \mathrm{~g}^{-1}$ because of introduction of the bulky, sterically more hindered SBI contortion site. $\mathrm{CO}_{2}$ adsorption of the polymers followed the same sequence as their $\mathrm{N}_{2}$-derived BET surface area: SBI-HTB > 6FDA-HTB (Figure 4b). The pore size distribution obtained from $\mathrm{CO}_{2}$ adsorption by NLDFT analysis (Figure S3) demonstrated ultra-microporosity $(<7 \AA)$ present in the Tröger's base-based 6FDA-HTB polyimide with a large fraction of ultra-micropores of $\sim 7 \AA$. 

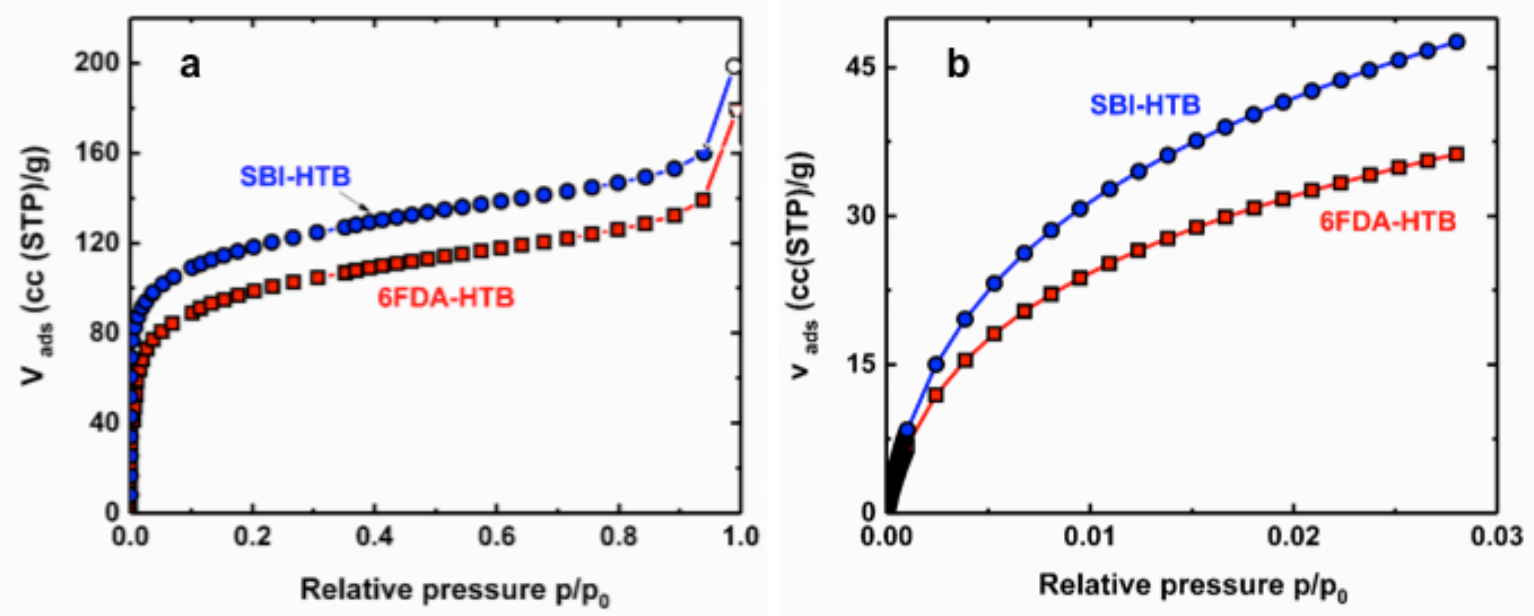

Figure 4. a) $\mathrm{N}_{2}$ adsorption isotherms of $6 \mathrm{FDA}-\mathrm{HTB}$ and $\mathrm{SBI}-\mathrm{HTB}$ at $-196{ }^{\circ} \mathrm{C}$; b) $\mathrm{CO}_{2}$ adsorption isotherms of 6FDA-HTB and SBI-HTB at $0{ }^{\circ} \mathrm{C}$.

Gas Permeation Properties. The gas permeation properties of the HTB-based polyimides were determined at 2 bar and $35{ }^{\circ} \mathrm{C}$ using the constant-volume/variable-pressure method (ESI). The gas permeabilities and gas-pair selectivities of 6FDA-HTB and SBI-HTB are compared with previously reported hydroxyl-functionalized 6FDA-derived PIM-PIs in Table 2 and some conventional low-free-volume 6FDA-based OH-containing PIs in Table S3. The permeabilities of all hydroxyl-based polyimides follow the sequence: $\mathrm{PH}_{2}>\mathrm{PCO}_{2}>\mathrm{PO}_{2}>$ $\mathrm{PN}_{2}>\mathrm{PCH}_{4}$. This trend can be ascribed to the size-selective chain packing of the polyimides due to the presence of ultra-micropores $(<7 \AA)$ as determined by gas sorption and NLDFT analysis. The 6FDA-HTB polyimide sample demonstrated significantly higher $\mathrm{H}_{2}, \mathrm{CO}_{2}$ and $\mathrm{O}_{2}$ permeabilities of 167,67 and 13.6 Barrer, respectively, compared to values reported for other 6FDA-based hydroxyl-functionalized polyimides without kinked contortion sites, such as 6FDA-HPI $\left(\mathrm{H}_{2}=68\right.$ Barrer $),{ }^{8}$ 6FDA-DAP $\left(\mathrm{H}_{2}=38\right.$ Barrer $){ }^{9}$ and 6FDA-DAR $\left(\mathrm{H}_{2}=34\right.$ Barrer) ${ }^{9}$ (Table S3). Furthermore, 6FDA-HTB showed the highest gas-pair selectivities of all presently reported $\mathrm{OH}$-functionalized PIM-PIs with $\mathrm{O}_{2} / \mathrm{N}_{2}, \mathrm{CO}_{2} / \mathrm{CH}_{4}$ and $\mathrm{H}_{2} / \mathrm{CH}_{4}$ selectivity values of $6.0,73$ and 181, respectively. Physical aging over a period of one month reduced the 
gas permeability by about 10 to $20 \%$ with a small increase in $\mathrm{H}_{2} / \mathrm{CH}_{4}, \mathrm{O}_{2} / \mathrm{N}_{2}$ and $\mathrm{CO}_{2} / \mathrm{CH}_{4}$ selectivity (Table 2). Introduction of the bulky spirobisindane-based dianhydride in the $\mathrm{OH}-$ functionalized Tröger's based polyimide (SBI-HTB) resulted in higher gas permeabilities for $\mathrm{H}_{2}$ (467 Barrer) and $\mathrm{CO}_{2}$ (466 Barrer) coupled with significant reductions in $\mathrm{H}_{2} / \mathrm{CH}_{4}(29)$, $\mathrm{CO}_{2} / \mathrm{CH}_{4}(29)$ and $\mathrm{O}_{2} / \mathrm{N}_{2}$ (4.6) selectivity.

Table 2. Gas Permeability and Permselectivity of 6FDA-HTB, SBI-HTB and Related OH-Functionalized 6FDA-derived PIM-PIs.

\begin{tabular}{lccccccccc}
\hline & \multicolumn{4}{c}{ Permeability (Barrer) } & \multicolumn{5}{c}{ Selectivity } \\
\cline { 2 - 9 } Polymer & $\mathrm{H}_{2}$ & $\mathrm{~N}_{2}$ & $\mathrm{O}_{2}$ & $\mathrm{CH}_{4}$ & $\mathrm{CO}_{2}$ & $\begin{array}{c}\mathrm{H}_{2} / \\
\mathrm{CH}_{4}\end{array}$ & $\begin{array}{c}\mathrm{N}_{2} / \\
\mathrm{CH}_{4}\end{array}$ & $\mathrm{O}_{2} /$ & $\mathrm{N}_{2}$ \\
\hline 6FDA-HTB $^{a}$ & 167 & 2.26 & 13.6 & 0.92 & 67 & 181 & 2.5 & 6.0 & 73 \\
6FDA-HTB $^{b}$ & 150 & 1.80 & 11.6 & 0.72 & 55 & 208 & 2.5 & 6.4 & 76 \\
SBI-HTB $^{a}$ & 467 & 16.6 & 75.7 & 16.3 & 466 & 29 & 1.0 & 4.6 & 29 \\
PIM-6FDA-OH $^{c}$ & 181 & 5.5 & 23.8 & 3.4 & 119 & 53 & 1.6 & 4.3 & 35 \\
6FDA-HSBF $^{d}$ & 162 & 3.8 & 19.3 & 2.4 & 100 & 68 & 1.6 & 5.1 & 42 \\
6FDA-DAT1-OH $^{e}$ & 127 & 2.7 & 14.0 & 1.4 & 70 & 91 & 1.9 & 5.4 & 50 \\
\hline
\end{tabular}

${ }^{\text {a) }}$ Fresh film was annealed at $250{ }^{\circ} \mathrm{C}$ under vacuum oven for $24 \mathrm{~h}$ before testing; ${ }^{\text {b) }}$ Film aged for 1 month; ${ }^{\text {c) }}$ Data from reference 47; ${ }^{\text {d) }}$ Data from reference $32 ;{ }^{\text {e) }}$ Data from reference 33.

$\mathrm{CO}_{2}$ and $\mathrm{CH}_{4}$ solubility coefficients $(S)$ were determined by gravimetric sorption at 2 bar pressure and $35{ }^{\circ} \mathrm{C}$ (Table 3). The diffusion coefficients $(D)$ were then calculated from the relationship $D=P / S$. 6FDA-HTB and SBI-HTB showed higher $\mathrm{CO}_{2}$ and $\mathrm{CH}_{4}$ solubility coefficients than PIM-6FDA-OH and 6FDA-HSBF, which can be ascribed to the higher BET surface area of HTB-based PIM-PIs. The $\mathrm{CO}_{2} / \mathrm{CH}_{4}$ solubility selectivities of the PIM-PIs varied only over a narrow range of 3.1-3.7. Similar results were obtained by direct gravimetric sorption of a Tröger's base PIM-PI derivative without OH-functionalization, 6FDA-TBDA, which showed a $\mathrm{CO}_{2} / \mathrm{CH}_{4}$ solubility selectivity of 3.4 at $35{ }^{\circ} \mathrm{C}$ and 2 bar. $^{48}$ Hence, no 
enhancement in solubility selectivity of $\mathrm{CO}_{2} / \mathrm{CH}_{4}$ was observed by introducing the tertiary amine-containing Tröger's base building block into the polymer main chain. Clearly, the remarkably high $\mathrm{CO}_{2} / \mathrm{CH}_{4}$ permselectivity of $6 \mathrm{FDA}-\mathrm{HTB}$ resulted exclusively from its higher $\mathrm{CO}_{2} / \mathrm{CH}_{4}$ diffusion selectivity (22.3) relative to other OH-functionalized PIM-PIs, such as SBI-HTB (9.2), PIM-6FDA-OH (9.5) and 6FDA-HSBF (11.8).

Table 3. $\mathrm{CO}_{2}$ and $\mathrm{CH}_{4}$ Diffusion Coefficients and Solubility Coefficients for 6FDA-HTB, SBI-HTB and Related OH-Functionalized PIM-PIs $\left(T=35^{\circ} \mathrm{C}, \mathrm{p}=2\right.$ bar $)$.

\begin{tabular}{llrlc}
\hline \multicolumn{1}{c}{ Polymer } & \multicolumn{2}{c}{$\begin{array}{c}\text { Diffusion coefficient } \\
\left(10^{-8} \mathrm{~cm}^{2} \mathrm{~s}^{-1}\right)\end{array}$} & \multicolumn{2}{c}{$\begin{array}{c}\text { Solubility coefficient } \\
\left(10^{-2} \mathrm{~cm}^{3}(\mathrm{STP}) \mathrm{cm}^{-3} \mathrm{~cm} \mathrm{Hg}^{-1}\right) \\
\mathrm{CO}_{4}\end{array}$} \\
\hline 6FDA-HTB & 2.47 & 0.11 & 27.2 & 8.3 \\
SBI-HTB & 14.5 & 1.55 & 32.7 & 11.5 \\
PIM-6FDA-OH & 5.48 & 0.58 & 21.7 & 5.9 \\
6FDA-HSBF & 4.65 & 0.39 & 21.4 & 6.0 \\
\hline
\end{tabular}

${ }^{a}$ Determined from $\mathrm{D}=\mathrm{P} / \mathrm{S}$ (S measured directly by gravimetric method); 2 bar, $35^{\circ} \mathrm{C}$;

${ }^{b}$ measured gravimetrically at 2 bar and $35^{\circ} \mathrm{C}$.

Table 4. $\mathrm{CO}_{2} / \mathrm{CH}_{4}$ Diffusion Selectivity and Solubility Selectivity for 6FDA-HTB, SBIHTB and Related OH-Functionalized PIM-PIs $\left(\mathrm{T}=35^{\circ} \mathrm{C}, \mathrm{p}=2\right.$ bar $)$.

\begin{tabular}{lcc}
\hline & $\begin{array}{c}\text { Diffusion selectivity }^{a} \\
(\alpha)_{\mathrm{D}}\end{array}$ & $\begin{array}{c}\text { Solubility selectivity }^{b} \\
\text { Polymer }\end{array}$ \\
\cline { 2 - 3 } & $\mathrm{CO}_{2} / \mathrm{CH}_{4}$ & $\mathrm{CO}_{2} / \mathrm{CH}_{4}$ \\
\hline 6FDA-HTB & 22.3 & 3.3 \\
SBI-HTB & 9.2 & 3.1 \\
PIM-6FDA-OH & 9.5 & 3.7 \\
6FDA-HSBF & 11.8 & 3.5 \\
\hline
\end{tabular}

${ }^{a}$ Determined from $\mathrm{D}=\mathrm{P} / \mathrm{S}$ (S measured directly by gravimetric method); 2 bar, $35^{\circ} \mathrm{C}$.

${ }^{b}$ Measured gravimetrically at 2 bar and $35^{\circ} \mathrm{C}$.

Previous studies of polyimides demonstrated that hydroxyl-functionalization in the polymer backbone leads to strong charge-transfer complex (CTC) formation that results in 
tighter interchain packing leading to enhanced gas-pair selectivity compared to unfunctionalized PIs. ${ }^{9,25}$ Here, we propose that the enhanced size-sieving properties of the 6FDA-HTB polyimide originated from strong hydrogen bonding. Three potential types of hydrogen bonding that may occur in $\mathrm{OH}$-functionalized polyimides are schematically illustrated for PIM-6FDA-OH and 6FDA-HTB in Figure 5. Intrachain- (Type I) and interchain (Type II) O-H $\cdots \mathrm{O}$ hydrogen bonding can occur in both types of PIM-PIs. In addition, strong interchain (Type III) $\mathrm{O}-\mathrm{H}^{\cdots} \mathrm{N}$ hydrogen bonding between the $\mathrm{N}$ atoms of the Tröger's base and OH group can be present in 6FDA-HTB (Figure 2b).

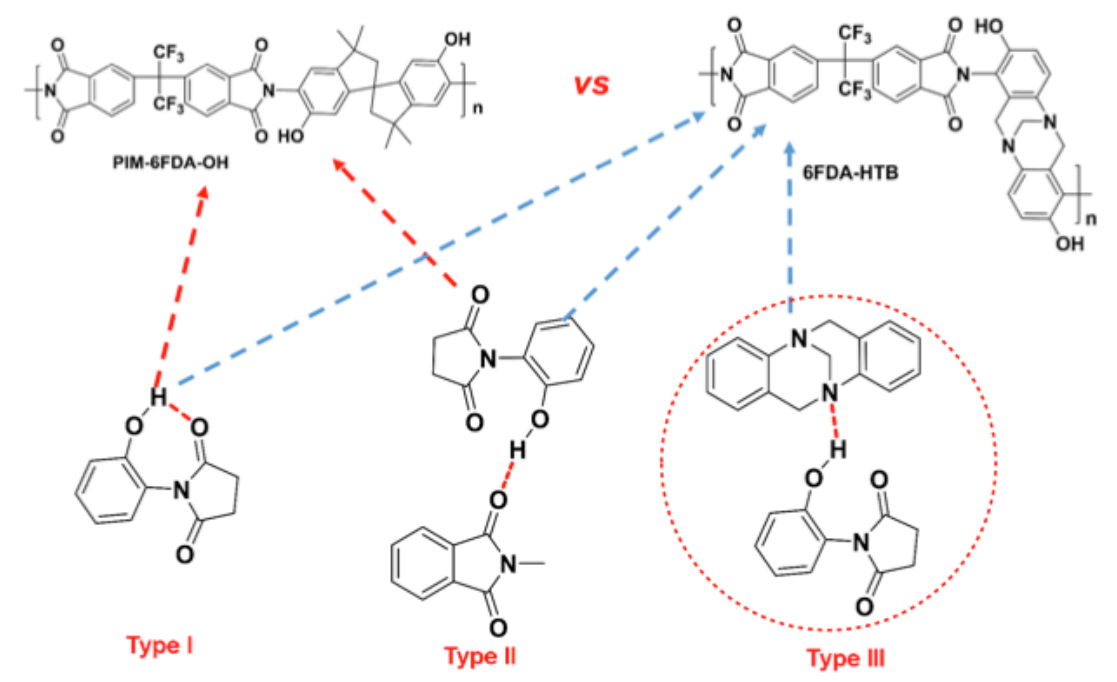

Figure 5. Potential hydrogen bonding types in PIM-6FDA-OH and 6FDA-HTB. Type I and II $(\mathrm{O}-\mathrm{H} \cdots \mathrm{O})$ can occur in both polyimides; Type III $(\mathrm{O}-\mathrm{H} \cdots \mathrm{N})$ can only be present in 6FDAHTB.

The performance of the HTB-derived PIM-PIs for $\mathrm{O}_{2} / \mathrm{N}_{2}, \mathrm{H}_{2} / \mathrm{CH}_{4}, \mathrm{H}_{2} / \mathrm{N}_{2}$ and $\mathrm{CO}_{2} / \mathrm{CH}_{4}$ separations is illustrated in Figure 6 relative to the 2008 and 2015 permeability/selectivity upper bounds. ${ }^{19,49}$ 6FDA-HTB exhibited the highest gas-pair selectivities of all OH-based PIM-PIs with performance on or above the 2008 trade-off line for $\mathrm{H}_{2} / \mathrm{N}_{2}, \mathrm{H}_{2} / \mathrm{CH}_{4}$, and $\mathrm{CO}_{2} / \mathrm{CH}_{4}$ but below the more recently reported 2015 upper bound line. Introduction of the OH-containing Tröger's base in 6FDA-HTB resulted in enhanced gas permeability without significant drop in gas-pair selectivity compared to low-free-volume PIs, such as 6FDA-DAP 
and 6FDA-HPI (Table S3). 6FDA-HTB showed 2-fold higher $\mathrm{CO}_{2} / \mathrm{CH}_{4}$ selectivity (73 vs 33) and 10-fold higher $\mathrm{CO}_{2}$ permeability (67 vs 6.6 Barrer) than the standard industry membrane material, cellulose triacetate (CTA), making it a promising candidate material for membranebased $\mathrm{CO}_{2} / \mathrm{CH}_{4}$ separation in natural gas and biogas applications.
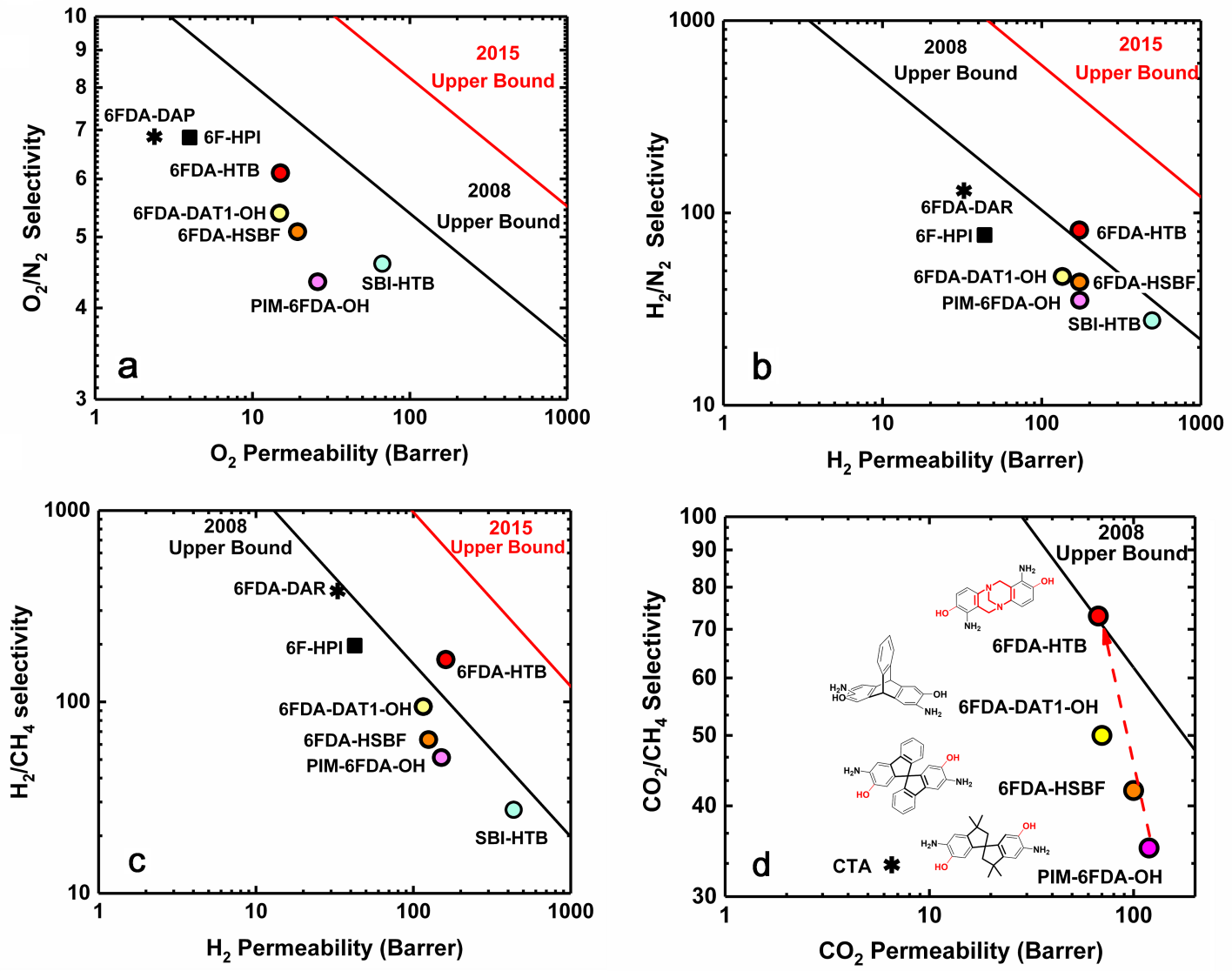

Figure 6. a) $\mathrm{O}_{2} / \mathrm{N}_{2}$, b) $\mathrm{H}_{2} / \mathrm{N}_{2}$, c) $\mathrm{H}_{2} / \mathrm{CH}_{4}$ and d) $\mathrm{CO}_{2} / \mathrm{CH}_{4}$ permeability/selectivity performance upper bound plots for PIM-PIs (6FDA-HTB, SBI-HTB, PIM-6FDA-OH, 6FDA-HSBF, 6FDA-DAT1-OH, colored symbols) and low-free-volume OHfunctionalized polyimides (6FDA-HPI, 6FDA-DAP, 6FDA-DAR, black symbols). CTA data are from reference 50 . 


\section{CONCLUSIONS}

A novel hydroxyl-functionalized Tröger's base diamine, 1,7-diamino-6H,12H-5,11methanodibenzo[1,5]diazocine-2,8-diol (HTB), was synthesized by a facile two-step method. Two intrinsically microporous $\mathrm{OH}-$ functionalized polyimides, 6FDA-HTB and SBI-HTB, demonstrated good solubility in polar solvents and exhibited high thermal stability of $380{ }^{\circ} \mathrm{C}$. 6FDA-HTB displayed the highest gas-pair selectivities to date of all currently reported OH-based PIM-PIs combined with commendable gas permeabilities. Specifically, 6FDA-HTB showed promising performance for membrane-based natural gas and biogas treatment with $\mathrm{CO}_{2}$ permeability of 67 Barrer and $\mathrm{CO}_{2} / \mathrm{CH}_{4}$ selectivity of 73 . The enhanced $\mathrm{CO}_{2} / \mathrm{CH}_{4}$ permselectivity originated from a very high diffusion selectivity of 22.3 , whereas the solubility selectivity of 3.3 was a typical value for polyimides. It is suggested that the highly size-selective chain packing of 6FDA-HTB was caused by strong $\mathrm{O}-\mathrm{H} \cdots \mathrm{N}$ interchain hydrogen bonding between the $\mathrm{OH}$ group and the nitrogen of tertiary amine in the Tröger's base unit.

\section{ASSOCIATED CONTENT}

\section{Supporting Information}

The Supporting Information is available free of charge on the ACS Publications website at DOI:

Gas permeation testing procedure, solubility properties, mechanical properties, TGA and TGA-MS, DSC, pore size distributions, gas transport properties. Crystallographic data of 1,7dinitro-6H,12H-5,11-methanodibenzo[1,5] diazocine-2,8-diol (CCDC 1545701). These data can be obtained free of charge from The Cambridge Crystallographic Data Centre via www.ccdc.cam.ac.uk/data_request/cif.

\section{AUTHOR INFORMATION}

\section{Corresponding Author}

*E-mail: ingo.pinnau@kaust.edu.sa 


\section{ORCID}

Ingo Pinnau: 0000-0003-3040-9088

\section{Notes}

The authors declare no competing financial interest.

\section{ACKNOWLEDGEMENTS}

This work was supported by funding from King Abdullah University of Science and Technology (KAUST).

\section{REFERENCES}

(1) Stern, S. A. Polymers for Gas Separations: The Next Decade. J. Membr. Sci. 1994, 94, 165 .

(2) Scholes, C. A.; Stevens, G. W.; Kentish, S. E. Membrane Gas Separations Applications in Natural Gas Processing. Fuel 2012, 96, 15-28.

(3) Sanders, D. F.; Smith, Z. P.; Guo, R.; Robeson, L. M.; McGrath, J. E.; Paul, D. R.; Freeman, B. D. Energy-Efficient Polymeric Gas Separation Membranes for a Sustainable Future: a Review. Polymer 2013, 54, 4729-4761.

(4) Baker, R. W.; Low, B. T. Gas Separation Membrane Materials: a Perspective. Macromolecules 2014, 47, 6999-7013.

(5) Hoehn, H. H.; Richter, J. W. Aromatic Polyimide, Polyester and Polyamide Separation Membranes. US Patent 3,899, 309 (1975).

(6) Kim, T. H.; Koros, W. J.; Husk, G. R.; O’Brien, K. C. Relationship Between Gas Separation Properties and Chemical Structure in a Series of Aromatic Polyimides. J. Membr. Sci. 1988, 37, 45-62.

(7) Stern, S. A.; Kawakami, H.; Houde, A.Y.; Zhou, G. Material and Process for Separating Carbon Dioxide from Methane, US Patent 5,591,250 (1997).

(8) Jung, C. H.; Lee, Y. M. Gas Permeation Properties of Hydroxyl-Group Containing Polyimide Membranes. Macromol. Res. 2008, 16, 555-560.

(9) Alaslai, N.; Ghanem, B.; Alghunaimi, F.; Litwiller, E.; Pinnau, I. Pure- and Mixed-Gas Permeation Properties of Highly Selective and Plasticization Resistant Hydroxyl-DiamineBased 6FDA Polyimides for $\mathrm{CO}_{2} / \mathrm{CH}_{4}$ Separation. J. Membr. Sci. 2016, 505, 100-107.

(10) Budd, P. M.; Elabas, E. S.; Ghanem, B. S., Makhseed; S., McKeown, N. B.; Msayib, K. J.; Tattershall, C. E.; Wang, D. Solution-Processed, Organophilic Membrane Derived from a Polymer of Intrinsic Microporosity. Adv. Mater. 2004, 16, 456-459. 
(11) Budd, P. M.; Ghanem, B. S.; Makhseed, S., McKeown, N. B.; Msayib, K. J.; Tattershall, C. E. Polymers of Intrinsic Microporosity (PIMs): Robust, Solution-Processable, Organic Nanoporous Materials. Chem. Commun. 2004, 230-231.

(12) Budd, P.; Msayib, K.; Tattershall, C.; Ghanem, B.; Reynolds, K.; McKeown, N.; Fritsch,

D. Gas Separation Membranes from Polymers of Intrinsic Microporosity. J. Membr. Sci. 2005, 251, 263-269.

(13) Guiver, M. D.; Lee, Y. M. Polymer Rigidity Improves Microporous Membranes, Science 2013, 339, 284-285.

(14) Kim, S.; Lee, Y. M. Rigid and Microporous Polymers for Gas Separation Membranes, Prog. Polym. Sci. 2015, 43, 1-32.

(15) McKeown, N. B. The Synthesis of Polymers of Intrinsic Microporosity (PIMs). Sci China Chem. 2017, 60, 1023-1032.

(16) Ghanem, B. S.; McKeown, N. B.; Budd, P. M., Selbie; J. D., Fritsch, D. High Performance Membranes from Polyimides with Intrinsic Microporosity. Adv. Mater. 2008, 20, 2766-2771.

(17) Ghanem, B. S.; McKeown, N. B.; Budd, P. M.; Al-Harbi, N. M.; Fritsch, D.; Heinrich, K.; Starannikova, L.; Tokarev, A.; Y. Yampolskii, Y. Synthesis, Characterization, and Gas Permeation Properties of a Novel Group of Polymers: PIM-Polyimides. Macromolecules 2009, 42, 7881-7888.

(18) Rogan, Y.; Starannikova, L.; Ryzhikh, V.; Yampolskii, Y.; Bernardo, P.; Bazzarelli, F.; Jansen, J. C.; McKeown, N.B. Synthesis and Gas Permeation Properties of Novel Spirobisindane-Based Polyimides of Intrinsic Microporosity. Polym. Chem. 2013, 4, 38133820 .

(19) Robeson, L. M. The Upper Bound Revisited. J. Membr. Sci. 2008, 320, 390-400.

(20) Rogan, Y.; Malpass-Evans, R.; Carta, M.; Lee, M.; Jansen, J. C.; Bernardo, P.; Clarizia, G.; Tocci, E.; Friess, K.; Lanč, M.; McKeown, N. B. A Highly Permeable Polyimide with Enhanced Selectivity for Membrane Gas Separations. J. Mater. Chem. A 2014, 2, 4874-4877. (21) Ghanem, B. S.; Swaidan, R.; Litwiller, E.; Pinnau, I. Ultra-Microporous Triptycenebased Polyimide Membranes for High-Performance Gas Separation. Adv. Mater. 2014, 26, 3688-3692.

(22) Ghanem, B.; Alghunaimi, F.; Ma, X.; Alaslai, N.; Pinnau, I. Synthesis and Characterization of Novel Triptycene Dianhydrides and Polyimides of Intrinsic Microporosity Based on 3,3'-Dimethylnaphthidine. Polymer 2016, 101, 225-232. 
(23) Ma, X.; Ghanem, B.; Salines, O.; Litwiller, E.; Pinnau, I. Synthesis and Effect of Physical Aging on Gas Transport Properties of a Microporous Polyimide Derived from a Novel Spirobifluorene-Based Dianhydride. ACS Macro Lett. 2015, 4, 231-235.

(24) Ma, X.; Abdulhamid, M. A.; Pinnau. I. Design and Synthesis of Polyimides Based on Carbocyclic Pseudo-Tröger's Base-Derived Dianhydrides for Membrane Gas Separation Applications. Macromolecules 2017, 50, 5850-5857.

(25) Swaidan, R.; Ghanem, B.; Litwiller, E.; Pinnau, I. Effects of Hydroxyl-Functionalization and Sub-Tg Thermal Annealing on High Pressure Pure-and Mixed-Gas $\mathrm{CO}_{2} / \mathrm{CH}_{4}$ Separation by Polyimide Membranes Based on 6FDA and Triptycene-Containing Dianhydrides. J. Membr. Sci. 2015, 475, 571-581.

(26) Alaslai, N.; Ghanem, B.; Alghunaimi, F.; Pinnau, I. High-Performance Intrinsically Microporous Dihydroxyl-Functionalized Triptycene-Based Polyimide for Natural Gas Separation. Polymer 2016, 91, 128-135.

(27) Alghunaimi, F.; Ghanem, B.; Alaslai, N.; Mukaddam, M.; Pinnau, I. Triptycene Dimethyl-Bridgehead Dianhydride-Based Intrinsically Microporous Hydroxyl-Functionalized Polyimide for Natural Gas Upgrading. J. Membr. Sci. 2016, 520, 240-246.

(28) Luo, S.; Wiegand, J. R.; Kazanowska, B.; Doherty, C. M.; Konstas, K.; Hill, A. J.; Guo, R. Finely Tuning the Free Volume Architecture in Iptycene-Containing Polyimides for Highly Selective and Fast Hydrogen Transport. Macromolecules 2016, 49, 3395-3405.

(29) Ma, X.; Swaidan, R.; Belmabkhout, Y.; Zhu, Y. H.; Litwiller, E.; Jouiad, M.; Pinnau, I.; Han, Y. Synthesis and Gas Transport Properties of Hydroxyl-Functionalized Polyimides with Intrinsic Microporosity. Macromolecules 2012, 45, 3841-3849.

(30) Li, S.; Jo, H. J.; Han, S. H.; Park, C. H.; Kim, S.; Budd, P. M.; Lee, Y. M. Mechanically Robust Thermally Rearranged (TR) Polymer Membranes with Spirobisindane for Gas Separation, J. Membr. Sci. 2013, 434, 137-147.

(31) Yi, S.; Ma, X.; Pinnau, I.; Koros, W. J. A High-Performance Hydroxyl-Functionalized Polymer of Intrinsic Microporosity for an Environmentally Attractive Membrane-Based Approach to Decontamination of Sour Natural Gas. J. Mater. Chem. A 2015, 3, 22794-22806. (32) Ma, X.; Salinas, O.; Litwiller, E.; Pinnau, I. Pristine and Thermally-Rearranged Gas Separation Membranes from Novel o-Hydroxyl-Functionalized Spirobifluorene-Based Polyimides. Polym. Chem. 2014, 5, 6914-6922.

(33) Alaslai, N.; Ma, X.; Ghanem, B.; Wang, Y.; Alghunaimi, F.; Pinnau, I. Synthesis and Characterization of a Novel Microporous Dihydroxyl-Functionalized Triptycene-Diamine- 
Based Polyimide for Natural Gas Membrane Separation. Macromol. Rapid Commun. 2017, 38, 1700303.

(34) Carta, M.; Malpass-Evans, R.; Croad, M.; Rogan, Y.; Lee, M.; Rose, I.; McKeown, N. B. The Synthesis of Microporous Polymers Using Tröger's Base Formation, Polym. Chem. 2014, $5,5267-5272$.

(35) McKeown, N. B.; Carta, M.; Croad, M. Method for Producing Polymers Comprising Multiple Repeat Units of Bicyclic Diamines, US Patent 9,018,270 (2015).

(36) McKeown, N. B.; Carta, M. Polymers, Their Method of Manufacture and Use Thereof, US Patent 9,212, 261 (2015).

(37) Rúnarsson, Ö. V.; Artacho, J.; Wärnmark, K. The 125th Anniversary of the Tröger's Base Molecule: Synthesis and Applications of Tröger's Base Analogues. Eur. J. Org. Chem. 2012, 7015-7041.

(38) Wang, Z.; Wang, D.; Zhang, F.; Jian, J. Tröger's Base-Based Microporous Polyimide Membranes for High-Performance Gas Separation, ACS Macro Lett. 2014, 3, 597-601.

(39) Wang, Z.; Wang, D.; Jin, J. Microporous Polyimides with Rationally Designed Chain Structure Achieving High Performance for Gas Separation. Macromolecules 2014, 47, 74777483.

(40) Zhuang,Y.; Seong, J. G.; Do, Y. S.; Jo, H. J.; Cui, Z.; Lee, J.; Lee, Y. M.; Guiver, M. D. Intrinsically Microporous Soluble Polyimides Incorporating Tröger's Base for Membrane Gas Separation, Macromolecules 2014, 47, 3254-3262.

(41) Zhuang, Y.; Seong, J. G.; Do, Y. S.; Lee, W. H.; Lee, M. J.; Guiver, M. D.; Lee, Y. M. High-Strength, Soluble Polyimide Membranes Incorporating Tröger's Base for Gas Separation, J. Membr. Sci. 2016, 504, 55-65.

(42) Ghanem, B.; Alaslai, N.; Miao, X.; Pinnau, I. Novel 6FDA-Based Polyimides Derived from Sterically Hindered Tröger's Base Diamines: Synthesis and Gas Permeation Properties. Polymer 2016, 96, 13-19.

(43) Lee, M.; Bezzu, C. G.; Carta, M.; Bernardo, P.; Clarizia, G.; Jansen, J. C.; McKeown, N. B. Enhancing the Gas Permeability of Tröger's Base Derived Polyimides of Intrinsic Microporosity, Macromolecules 2016, 49, 4147-4154.

(44) Calle, M.; Lee, Y. M. Thermally Rearranged (TR) Poly(ether-benzoxazole) Membranes for Gas Separation. Macromolecules 2011, 44, 1156-1165.

(45) Neuhaus, D.; Williamson, M. P. The Nuclear Overhauser Effect in Structural and Conformational Analysis. Wiley-VCH, Weinheim, 2000.

(46) Emsley, J. Very Strong Hydrogen Bonding. Chem. Soc. Rev. 1980, 9, 91-124. 
(47) Salinas, O.; Ma, X.; Litwiller, E.; Pinnau, I. High-Performance Carbon Molecular Sieve Membranes for Ethylene/Ethane Separation Derived from an Intrinsically Microporous Polyimide. J. Membr. Sci. 2016, 500, 115-123.

(48) Abdulhamid, M. A.; Ma, X.; Miao, X.; Pinnau, I. Synthesis and Characterization of a Microporous 6FDA-Polyimide Made from a Novel Carbocyclic Pseudo Tröger's Base Diamine: Effect of Bicyclic Bridge on Gas Transport Properties. Polymer 2017, 130, 182-190. (49) Swaidan, R.; Ghanem, B.; Pinnau, I. Fine-Tuned Intrinsically Ultramicroporous Polymers Redefine the Permeability/Selectivity Upper Bounds of Membrane-Based Air and Hydrogen Separations. ACS Macro Lett. 2015, 4, 947-951.

(50) Puleo, A.C.; Paul, D. R.; Kelley, S.S. The Effect of Degree of Acetylation on Gas Sorption and Transport Behavior in Cellulose Acetate. J. Membr. Sci. 1989, 47, 301-332. 


\section{Table of Contents}

\section{Facile Synthesis of a Hydroxyl-Functionalized Tröger's}

Base Diamine: A New Building Block for High-Performance Polyimide Gas Separation Membranes

Xiaohua Ma, Mahmoud A. Abdulhamid, Xiaohe Miao, Ingo Pinnau*

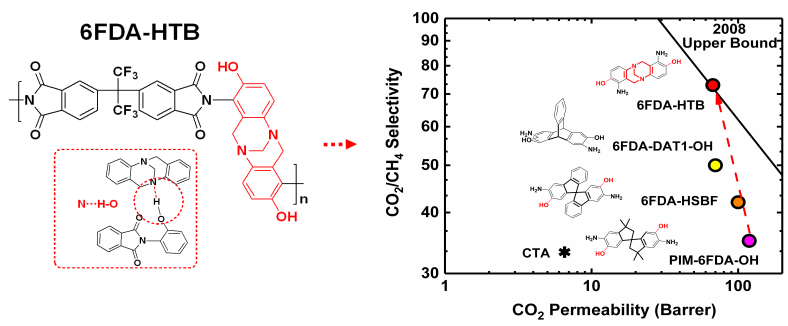

